\title{
Monseñor José Luis Lacunza, Ex Rector de la USMA, Primer Cardenal Panameño.
}

\section{Francisco Javier Blanco Lopezuazo ${ }^{1, *}$}

${ }^{1}$ Decabi de la Facultad de Humanidades, Universidad Santa María La Antigua (USMA), Apartado Postal 0819-08550, Panamá, República de Panamá

*Autor para correspondencia. Email: fblanco@usma.ac.pa

Recibido: 29 de marzo de 2015

Aceptado: 17 de abril de 2015

\section{La grata noticia}

Como ha sido anunciado, el próximo 14 de febrero tendré la alegría de celebrar un consistorio, durante el cual voy a nombrar 15 nuevos Cardenales, quienes proviniendo de 14 naciones de cada continente, manifiestan el vínculo inseparable entre la Iglesia de Roma y las Iglesias particulares presentes en el mundo. (Papa Francisco, 2015)

De esta manera, al final del acostumbrado rezo del “Ángelus” dominical del 4 de enero de 2015, poco después de las 12:00 meridiano en Roma, 6:00 de la mañana en Panamá, el Papa Francisco comienza un anuncio inesperado a la Iglesia universal, da a conocer el nombre de los próximos 20 cardenales de la Iglesia Católica que serían creados semanas después, durante el Consistorio Público del 14 de febrero en solemne ceremonia.

El nombre y apellido del que ocupa la posición número 13 de esa lista pronunciada en italiano, no resulta extraño a los oídos de los oyentes de habla hispana que están en la Plaza de San Pedro, ni a los radioescuchas y televidentes que siguen la intervención del Sumo Pontífice a lo largo y ancho del mundo: "Monseñor José Luis Lacunza Maestrojuán, Obispo de David, Panamá"

Primero perezosa e incrédulamente, después intensa y jubilosamente, como si de un reguero de pólvora se tratase, se corre la noticia que en muy poco tiempo llega hasta los rincones más recónditos de este pequeño país, sobre todo después de que el propio Monseñor Lacunza, igualmente sorprendido por el anuncio, y después de la necesaria verificación, él mismo comunica de viva voz la tan dichosa noticia a los fieles que asisten a la celebración eucarística dominical de la mañana que él mismo preside. 
Invest. pens. crit.

Vol. 3, No. 1 enero-abril 2015.

pp. $87-95$

\section{Significado e historia del cardenalato}

Ser Cardenal es la máxima dignidad a la que puede acceder un eclesiástico y sólo el Papa puede concederla. Los Cardenales de la Iglesia Católica son creados en Consistorio público y su misión es aconsejar y ayudar al Papa en el gobierno universal de la Iglesia y elegir a su sucesor cuando por muerte u otra circunstancia la Sede de Pedro queda vacante. Los Cardenales pueden ser obispos o arzobispos de sus respectivas diócesis o presidir los diversos dicasterios u organismos de la Curia romana para el gobierno de la Iglesia.

Etimológicamente la palabra Cardenal proviene de la palabra latina "cardinis" que significa gozne o bisagra sobre el que gira una puerta, como analogía de lo que será su función de facilitar y apoyar al Sumo Pontífice en el gobierno y administración de la Iglesia. Al desempeñar un papel fundamental en la Iglesia por extensión, la palabra cardinal se aplica a aquello que es lo más importante o fundamental de algo, como por ejemplo hacer referencia a las virtudes cardinales o principales o a los puntos cardinales o básicos para orientarnos.

Al principio, se utilizó esta palabra para designar a las personas incardinadas, pertenecientes o adscritas en una Iglesia donde iban a desarrollar sus funciones eclesiásticas. Más adelante, las comunidades, iglesias o parroquias cardinales eran aquellas que destacaban por su importancia o preminencia. Fusionando estos dos conceptos es que surge el sentido con el que se va a utilizar la palabra cardenal en la Iglesia más adelante.

El presbiterio o comunidad de sacerdotes de una Iglesia, y en concreto el presbiterio romano es el germen del concepto de cardenal actual en cuanto que era el cuerpo presbiteral de la Iglesia de Roma quien asistía y apoyaba a su Obispo que, a la postre era el jefe de la Iglesia universal, en la ejecución de su ministerio pastoral. El presbiterio romano, como el de todas las Iglesias o diócesis lo componían los presbíteros y diáconos de esa Iglesia. Con el aumento de su número y para hacer más eficiente su labor de apoyo se redujo a los representantes principales de las distintas iglesias y diaconías.

A partir del siglo IV, cuando el Obispo de Roma, aunque siempre había tenido la primacía por ser sucesor de Pedro, incrementa su incidencia en las demás iglesias locales, la acción consultiva y ejecutiva del presbiterio romano se hizo más directa en toda la cristiandad.

Durante el siglo VII, el presbiterio romano empezó a desempeñar funciones cuando se producía sede vacante o ausencia del Sumo Pontífice. Y lo hacía a través de un triunvirato que se convierte en antecedente de la estructura cardenalicia actual, pues lo componía el arcipreste, el arcediano y el primicerio, es decir, el más antiguo de los presbíteros, el más antiguo de los diáconos y el más antiguo de los notarios.

Con el Papa Juan VIII, en el siglo IX, se reorganizó el consistorio o asamblea general de los cardenales. A los cardenales presbíteros que lo conformaban se les unieron los obispos suburbicarios, es decir los obispos sufragáneos (adscritos, por ejemplo, las diócesis de Colón-Kuna Yala, Santiago, Chitré y David, son diócesis sufragáneas de la Arquidiócesis de Panamá) del Papa, a quienes ya en el siglo VIII se 
les había atribuido el nombre de cardenales por su vinculación con la basílica de Letrán, la basílica del Papa u obispo de Roma.

La conformación del Colegio cardenalicio desde sus orígenes muestra una heterogeneidad que refleja la diversidad del presbiterio. La diferencia radica en el diferente grado del orden al que han llegado sus miembros, diáconos, presbíteros y epíscopos u obispos.

Aunque en la actualidad los encargados de elegir al Papa son los cardenales, no siempre fue así. Al principio lo hacía, como hemos visto los miembros de la Iglesia romana. A partir del año 1059, el Papa Nicolás II, con la constitución apostólica in nomine Domini, del Concilio Particular de Letrán, limitó este derecho a los cardenales que fueran obispos. En 1179, el Papa Alejandro III, a través de la constitución Licet de vitanda discordia, del Concilio Ecuménico de Letrán, amplió a todos los cardenales este derecho. En 1274, el Papa Gregorio X determinó mediante la constitución apostólica Ubi periculum, del Concilio Ecuménico de Lyon, que la función más importante de los cardenales era la de elegir al Romano Pontífice y que para su elección eran necesarias las dos terceras partes de los cardenales reunidos.

En la edad moderna (siglos XIV-XVI), los monarcas españoles, franceses e ingleses nombraron en puestos de gobierno a cardenales de la Iglesia Católica. Los cardenales Thomas Wolsey, Alberioni, Cisneros, Mendoza, Richelieu y Mazarino, son algunos de los que más han destacado en intervenciones en sus respectivos estados.

Siempre, pero sobre todo a partir del siglo XX, los diferentes Papas han modificado el código de elección para adecuarla a las necesidades cambiantes de los tiempos, sobre todo en cuanto al número y edad de los electores. La última normativa emanada al respecto, la constitución apostólica Universe Dominici Gregis, de 1996, de San Juan Pablo II, establece que un cardenal para ser elector debe tener menos de 80 años al momento de producirse sede vacante y aunque no establece el número máximo de cardenales electores se ha mantenido en torno a los 120 que era la cantidad que en una anterior normativa había fijado el Papa Pablo VI.

Los símbolos de la dignidad del cardenalato son los siguientes:

- Capello: es un sombrero púrpura de cuatro lados. En la antigüedad lo usaban los esclavos que habían sido liberados y también lo usaban los ciudadanos libres en las grandes fiestas. Es símbolo de la libertad de la que gozan os todos los que somos hijos de Dios. En la actualidad no se usa y no se le impone en la ceremonia de creación de cardenales.

- Birreta: Hoy en día se impone en lugar del capello cardenalicio.

- El anillo: al igual que los obispos y el Papa lo usan en señal de unión y compromiso con la Iglesia. Los Cardenales lo usan en señal de su desposorio con la Iglesia de Roma, y por tanto con toda la Iglesia universal. 
Invest. pens. crit.

Vol. 3, No. 1 enero-abril 2015.

pp. $87-95$

- El color púrpura: que recuerda el color de la sangre, es señal de que los cardenales están dispuestos a mantenerse fieles en la fe incluso sufrir el martirio si ello fuera necesario.

La estructura del Colegio cardenalicio, atendiendo a su origen histórico que hemos reseñado anteriormente, se dividen en tres órdenes, cardenales del orden episcopal, cardenales del orden presbiteral y cardenales del orden diaconal. Las órdenes siguen la tradición de incardinación en la iglesia de Roma. Por eso al ser creados cardenales reciben una sede suburbicaria o sufragánea de Roma, un título o una diaconía que se corresponde con templos romanos que tienen este privilegio.

- Los cardenales obispos son los de mayor rango dentro del Colegio de Cardenales. Ostentan el episcopado en una de las siete diócesis suburbicarias o son Patriarcas de alguna Iglesia Oriental Católica. Las sedes suburbicarias son: Ostia, Velletri-Segni, Frascati, Porto-Santa Rufina, Albano, Palestrina y Sabina-Poggio Mirteto. Aunque sean titulares de estas diócesis no ejercen gobierno sobre ellas, pues cada una tiene su propio Ordinario para su gobierno. En la actualidad son tres cardenales obispos que son Patriarcas de iglesias orientales católicas: el patriarca emérito de Antioquía, de los Maroniatas, el Patriarca titular de la misma Iglesia de Antioquía, de los Maronitas y el Patriarca emérito de Alejandría de la Iglesia Copta. El cardenal Decano de este orden es el primero entre pares. Es elegido por ellos mismos entre los cardenales de este orden. El título que ostenta el cardenal Decano es el de Ostia, además del que le había sido asignado.

- Los cardenales presbíteros son los que se les ha asignado un título o templo de la diócesis de Roma. Suelen crearse cardenales en este orden a los que son obispos titulares de alguna diócesis. Al Cardenal José Luis Lacunza Maestrojuán se le asignó el templo de San José de Cupertino. Estos títulos son también honoríficos, pues más allá del protocolo no pueden intervenir en los asuntos ordinarios de las mismas.

- Los cardenales diáconos son los que han recibido una diaconía de alguna iglesia de las 28 iglesias de la ciudad de Roma que gozan de este privilegio. Suelen ser adscritos al orden diaconal los cardenales que no fungen como obispos en ninguna diócesis, sino que tienen altas responsabilidades en la Curia romana o se han distinguido en algún otro campo. El Cardenal más antiguo de este orden es el Cardenal Protodiácono y entre sus funciones está la de anunciar, después de concluido el cónclave, a la muchedumbre la persona que fue elegida Papa y el nombre que ha elegido para desarrollar su ministerio petrino. Inicia su anuncio con las famosas palabras en latín "Annuntio vobis gaudium magnum: habemus papam", que significan "Os anuncio una gran alegría: tenemos Papa". También es el encargado de imponer el palio a los nuevos arzobispos metropolitanos.

- Cuando no es conveniente, por algún motivo especial, hacer público el nombre de alguno de los elegidos por el Papa para ser creado cardenal, el Papa puede mantenerlo en secreto. En este caso es un "Cardenal in pectore". Si las condiciones varían puede hacerse público. Si el Papa muere sin haberlo anunciado, el cardenalato se extingue. 
Invest. pens. crit. Vol. 3, No. 1, enero-abril 2015.

pp. $87-95$

El trato protocolar que se le da a los cardenales es el de "Su Eminencia" y si el cardenal es obispo o arzobispo se le trata de "Su Eminencia Reverendísima". También es tradicional que el título de Cardenal forme parte del nombre. A Monseñor Lacunza, de manera formal se le pondría nombrar también: "José Luis Cardenal Lacunza Maestrojuán”. Algunos cardenales utilizan en la rúbrica "S.R.E. Cardinalis", que en latín es Sanctae Romanae Ecclesiae Cardinalis (Cardenal de la Santa Iglesia Romana.)

\section{Cardenal José Luis Lacunza Maestrojuán. Séptimo rector de la USMA}

Nació el 24 de noviembre de 1944 en la ciudad de Pamplona, Reino de Navarra, España. José Luis hizo los estudios de bachillerato en el Seminario Menor San José, de los Agustinos Recoletos, en Artieda, Navarra, y de Filosofía en el Seminario Nuestra Señora de la Valentuñana, en Sos del Rey Católico, Zaragoza.

Continuó sus estudios en el Seminario agustino recoleto de Pamplona donde realizó los estudios de Teología. Profesó los votos simples el 14 de septiembre de 1964, en Pamplona, y los votos solemnes tres años después. Fue ordenado sacerdote el 13 de julio de 1969 en Pamplona también, su ciudad natal.

Se desempeñó, en primer lugar como profesor de latín y religión en el colegio de los Agustinos Recoletos Nuestra Señora del Buen Consejo, de Madrid. En 1976 llegó a Panamá, al colegio San Agustín, donde enseñó Latín, Matemáticas, Filosofía, religión, Artística y Sociología. En la Universidad de Panamá obtuvo la Licenciatura en Filosofía e Historia, con la tesis de grado: "Fundamento espiritual de la Edad Media". Ocupó la Rectoría del colegio San Agustín desde 1979 a 1985.

Como Presidente de la Federación de Colegios Católicos de Panamá, fue miembro de la Junta de Directores de la Universidad Católica Santa María la Antigua de 1980 a 1985. En junio de ese mismo año tomó posesión del cargo de Rector Magnífico de la USMA. Como tal, propuso una revisión de los Estatutos, a fin de que estuviesen más a tono con la realidad universitaria del momento. Le toca dirigir a la universidad durante un lustro que fue un período sumamente difícil para la vida nacional de Panamá y en medio de esos difíciles momentos supo infundir ánimo y mística a estudiantes y colaboradores para poder salir adelante. (Comisión de los 50 años de la USMA, Memoria Institucional, manuscrito en preparación)

Fue nombrado Obispo Auxiliar de Panamá, en 1985, y recibe la ordenación episcopal el 18 de enero de 1986, y se le asigna la sede titular de Partenia. El 29 de octubre de 1994, es nombrado obispo de Chitré, diócesis que pastorea por cinco años. El 28 de agosto de 1999 es nombrado obispo de la diócesis de David. Monseñor Lacunza siempre se ha distinguido por propiciar un clima de paz y de diálogo entre los diferentes estamentos de la sociedad panameña. Es de destacar su actuación de mediación en procesos electorales en la república y más recientemente, como Pastor de la diócesis de David, ha intervenido activa y eficazmente en procesos de diálogos en confrontaciones entre el gobierno e indígenas por sus reivindicaciones en temas de minería y de centrales hidroeléctricas. 
Invest. pens. crit.

Vol. 3, No. 1 enero-abril 2015.

pp. $87-95$

De igual forma ha sido muy relevante su acción dentro de la Conferencia Episcopal Panameña donde en varias ocasiones se ha desempeñado como su Presidente y ha destacado también su participación en los Departamentos de Educación y Cultura y también en el Departamento de Pastoral Social. También en el Consejo Episcopal Latinoamericano (CELAM) se ha destacado en el desempeño dentro del Departamento de Cultura. Participó activamente en la IV Conferencia General del Episcopado Latinoamericano celebrada en 1992, en Santo Domingo y en la V Conferencia General del Episcopado Latinoamericano y del Caribe, celebrada en 2007, en Aparecida, Brasil. Precisamente formó parte, junto al entonces Cardenal Jorge Bergoglio y a otros obispos, de la Comisión que redactó el documento conclusivo de esta Conferencia General del Episcopado celebrada en Aparecida.

Tras el anuncio del Papa Francisco que encabeza este escrito, el 14 de febrero de 2015, Monseñor José Luis Lacunza Maestrojuán fue creado Cardenal de la Iglesia Católica en el Consistorio público de esa fecha. Es el primer Cardenal panameño y el primero de la Orden de Agustinos Recoletos. Recientemente fue asignado por el Papa Francisco responsabilidades en la Congregación para la Educación Católica y en el Pontificio Consejo para la Cultura.

\section{Significado para para la Iglesia y para la nación panameña}

Ante todo, indicar que es para la Iglesia y para la nación panameñas un honor que uno de sus hijos se le haya elevado a esta dignidad. Pero más allá del honor que esto supone, detrás de la creación de Monseñor José Luis Lacunza como Cardenal de la Iglesia Católica por parte del Papa Francisco, podemos encontrar significados y lecturas que le atañen a él como persona, a los católicos que formamos parte de esta Iglesia que peregrina en Panamá y a todos los que somos panameños, independientemente de la fe religiosa que profesemos cada quien.

No cabe duda que cuando el Papa se fija en una persona para crearle cardenal se fija en sus características personales y en las características y condiciones de la Iglesia y del país al que representaría.

Como persona, Monseñor José Luis Lacunza, se destaca como alguien activo y apasionado, directo en sus planteamientos y cercano a todos, conciliador y, al mismo tiempo, decidido en todo cuanto cree que debe emprender. Características que han hecho que en todos los cargos en los que se ha desempeñado, profesor, Rector del Colegio san Agustín, Rector de la Universidad Santa María la Antigua, Obispo Auxiliar de Panamá, Obispo de Chitré, Obispo de David y en los departamentos y comisiones de la Conferencia Episcopal Panameña (CEP) y del Consejo Episcopal Latinoamericano (CELAM) su presencia haya sido importante para conseguir las metas y objetivos perseguidos sin que nadie se haya podido sentir excluido.

Tener credibilidad y poder de convocatoria para reunir a personas con ideas y posturas a primera vista irreconciliables, y después conseguir senderos de entendimiento para lograr acuerdos e incluso poder seguir trabajando juntos es propio de personas con gran profundidad que pueden alcanzar a ver las raíces de la problemática y, por consiguiente, las vías de superación que sean aceptables para todas las partes. Su buen hacer en el papel de mediador, como representante de la Iglesia panameña, en torneos 
electorales y en conflictos sobre minería y centrales hidroeléctricas entre distintos grupos acaecidos en Panamá son prueba inequívoca de su gran capacidad de diálogo y de mediación tan necesarios en nuestra sociedad en el ámbito universal.

Su gran labor cuando ha sido responsable tanto de la Conferencia Episcopal Panameña (CEP), como del Consejo Episcopal Latinoamericano (CELAM), sobre todo en departamentos que tienen que ver con Cultura, Educación y Pastoral Social ha sido de sobra reconocida. No en vano las primeras asignaciones del Papa Francisco al nuevo Cardenal Lacunza están en la Congregación de Educación Católica y en el Pontificio Consejo para la Cultura.

Es de suma importancia su participación en la Comisión que tuvo a su cargo la redacción final del Documento Conclusivo de Aparecida, en la V Conferencia General del Episcopado Latinoamericano y del Caribe, donde tuvo la dicha de compartir esta experiencia bajo la dirección del entonces Cardenal Jorge Bergoglio. En ese documento generado por el episcopado latinoamericano, pero dado forma por los integrantes de esta Comisión, ya se ponen de manifiesto y se presentan modelos de Iglesia y nuevas formas de vivir el cristianismo adecuados a la nueva realidad en la que esta Iglesia está inmersa.

Es pues, a nivel personal para Monseñor Lacunza, a la vez que un honor haber sido llamado por el Papa para ser creado Cardenal de la Iglesia Católica, una gran responsabilidad el cumplir con el servicio de ayudar y aconsejar al Papa en el gobierno universal de la Iglesia en estos momentos tan decisivos por los que atraviesa.

Para la Iglesia panameña que peregrina en Panamá es también un honor, un reconocimiento y una responsabilidad.

Un honor porque dado que la selección de los Cardenales, como apoyo al Papa en el gobierno de la Iglesia Universal, responde a una representatividad de lo que es esa Iglesia local de cara a la Iglesia Universal, el que por primera vez un Pastor panameño entre en esa responsabilidad tan singular, no deja de ser un hito y vuelve a poner a la Iglesia panameña en un sitial de relieve en el concierto de la Iglesia universal.

Es un reconocimiento porque, como señalaba el Arzobispo de Panamá, Monseñor José Domingo Ulloa, la creación del Obispo de David como Cardenal, es reconocer a la Iglesia panameña el mérito, el servicio y la importancia de haber sido la Iglesia desde donde se irradió la fe a Tierra Firme, que no es otra cosa que a todo el continente americano. La celebración, hace poco más de un año, de los 500 años de la erección de Santa María la Antigua como la primera diócesis en Tierra Firme, era un acontecimiento que no podía pasar desapercibido para la Iglesia de América y tampoco para la Iglesia universal. La creación de nuestro primer Cardenal es una forma de reconocer este servicio que nuestra Iglesia brindó.

Pero todo honor y todo reconocimiento debe ser correspondido con una responsabilidad. Al respecto, el mismo Cardenal José Luis Lacunza, desde los primeros momentos, incluso cuando ni él mismo, ni 
Invest. pens. crit.

Vol. 3, No. 1 enero-abril 2015.

pp. $87-95$

la misma sociedad panameña habíamos asimilado por completo el significado que la tan magna noticia traía consigo, lo primero que pide, después de agradecer al Santo Padre su gesto y deferencia, es oraciones para poder cumplir a cabalidad la misión tan especial que desde ese momento se le encomendaba.

Más sosegado, casi tres meses después de haber recibido la noticia, en un homenaje que se le hace por parte de la Iglesia panameña y que luego se recoge en un interesante artículo en el semanario Panorama Católico, él expresa que Monseñor Marcos Gregorio MacGrath debía haber sido el primer Cardenal panameño y dice que la Iglesia no debe perder la memoria de quien fuera su gran Pastor por casi treinta años.

Más allá de la alusión a quien sin duda fue un gran Arzobispo después del Concilio Vaticano II, es un llamado a retomar y a vivir según ese modelo de Iglesia que desde su primera Carta Pastoral, allá por el año 1971, ya planteaba. Un modelo de Iglesia que surge del Concilio Vaticano II, un modelo que se desgrana a través de todas sus Constituciones, Decretos y Declaraciones y que da luces para adecuar lo que debía ser la Iglesia para esa parte final del siglo XX y lo que debe ser para este siglo XXI del que ya llevamos 15 años. Ese mensaje es una invitación a retomar con fuerza nuestra vivencia cristiana orientada por los documentos eclesiales y los planes de Pastoral de cada diócesis.

Esa es nuestra gran responsabilidad como Iglesia panameña que ha sido bendecida con la creación de un Cardenal de nuestro suelo. Nuestra vivencia vigorosa de nuestro cristianismo dará fuerzas, ideas y experiencias que le serán de gran provecho a nuestro Cardenal en ese apoyo y consejo que le debe brindar al Santo Padre.

Una vivencia tibia de nuestro ser Iglesia, por el contrario, podría minar su entusiasmo y, en todo caso, no encontraría inspiración para la delicada misión que tiene encomendada. Es simple aplicación de la verdad revelada de la comunión de los santos y del concepto del cuerpo místico de Cristo que es la Iglesia, donde el bien de unos redunda en el beneficio de todos, pero donde el mal de algunos también repercute en perjuicio de todos. Nos sentimos orgullosos y felices por la designación, sintámonos, pues, también, desde nuestro lugar en la Iglesia, responsables que, a fin de cuenta, no es sólo de él, también es nuestra esa designación.

Finalmente, la creación de Monseñor José Luis Lacunza como Cardenal, también tiene una incidencia para Panamá como país y para los panameños, independientemente de sus creencias religiosas, como dije anteriormente.

Efectivamente, también es un orgullo para el país que un panameño haya sido elevado a esa dignidad y tenga esa responsabilidad en una institución tan importante y de tanta credibilidad en el mundo como es la Iglesia. En este sentido es una manera de volver a ser un país que, aunque pequeño, juega un papel importante en el concierto de todos los países. 
Monseñor José Luis Lacunza, ayudado por su rica personalidad, podrá llevar a un ámbito más universal aquellas características que nos son propias como país. El ser "puente del mundo y corazón del universo" y el lema que reza nuestro escudo: "Pro mundi beneficio" ha sido la impronta que nuestro pequeño país siempre ha llevado enarbolada y en no pocas y difíciles situaciones ha sabido dar una respuesta o una salida a cuestiones que parecían insolventes y la acción de nuestro pequeño país, sirvió para solventarlas.

El ser apoyo y consejero del Papa en un medio tan complejo que vive nuestro mundo de hoy, no cabe duda que hacerlo con el talante de su personalidad que encierra, al mismo tiempo, en gran medida nuestra identidad como panameños aportará esos aires de diálogo, tolerancia y convivencia fraterna que tanto necesita nuestro mundo.

\section{Conclusión}

A todo lo dicho anteriormente, sólo quiero agregar que si de quien estamos hablando y nos llena de tanto orgullo a la Iglesia y al País, fue además Rector Magnífico de la Universidad Católica Santa María la Antigua, esa alegría y esa satisfacción se incrementa enormemente en toda la comunidad universitaria usmeña.

El que por así decir "uno de los nuestros" haya sido distinguido de esta manera nos obliga a corresponderle con ese buen hacer de nuestras obligaciones diarias como aporte y tributo a ese "usmeño" al que se le ha conferido esa responsabilidad tan grande.

Sí, estamos alegres y felices.

Sí, estamos orgullosos.

Pero, sobre todo, estamos comprometidos en aportar, desde nuestro puesto de cada día, esa responsabilidad que nos cabe por la creación del Cardenal José Luis Lacunza Maestrojuán.

Su Eminencia Reverendísima

"Ad multos annos"

\section{Referencias}

Comisión de los 50 años de la USMA. (2015). Memoria Institucional USMA [manuscrito en preparación]. Universidad Santa María la Antigua, Panamá.

Papa Francisco (4 de enero de 2015). Anuncio realizado después de la oración del Ángelus del 4 de enero de 2015. Recuperado de http://es.radiovaticana.va/news/2015/01/04/el papa anuncia la creaci $\%$ C3\%B3n de nu evos cardenales $/ 1116918$ 